\title{
The Role of Agricultural Production Economies in Achieving Food Security in Sudan during the Period (2015-2018) (A Case study of Sorghum, Millet and Wheat)
}

\author{
Elfatih Mohamed Osman Mukhtar
}

Associate Professor, Qassim University, Department of Economics \& Finance, College of Business and Economics, Buraydah, Kingdom of Saudi Arabia

Correspondence Author: Elfatih Mohamed Osman Mukhtar, Associate Professor, Qassim University, Department of Economics \& Finance, College of Business and Economics, Buraydah, Kingdom of Saudi Arabia.

E-mail:- drelfatih@hotmail.com

Received date: 25 August 2019, Accepted date: 30 September 2019, Online date: 22 November 2019

Copyright: (C) 2019 Elfatih Mohamed Osman Mukhtar, This is an open-access article distributed under the terms of the Creative Commons Attribution License, which permits unrestricted use, distribution, and reproduction in any medium, provided the original author and source are credited.

\begin{abstract}
This study aimed to identify the role of agricultural production economies in achieving food security in Sudan during the period 2015 - 2018 (A case study of sorghum, millet and wheat) by recognizing the concept of agricultural production economies and its objectives and the factors that influence the agricultural production. It also aims to identify the concept of food security and its dimensions. To achieve the objective of the study, the researcher followed the deductive approach to state the problem and the hypotheses. The study also followed the historical, analytical approach and case study approach to highlight the role of agricultural production economies in achieving food security in Sudan during the period 2015 - 2018. The study concluded with many results; the most important of which is that the productivity of the essential food crops (sorghum, millet and wheat) did not meet the local needs due to increase of prices of these crops significantly and the majority of the population is unable to afford to buy them. The results also showed that one of the main reasons that led to this meager production of the basic food crops (sorghum, millet and wheat) is the lack of financing of agricultural production. The imposition of heavy taxes and fees on farmers resulted in their reluctance to grow these crops, as well as the lack of fuel, and cash, fluctuation of rain, and all have a negative impact on food security. Moreover, the lack of security led to low production of sorghum and millet where they are grown in Darfur, Blue Nile State, and Kordofan and Nuba mountains. These regions are areas of conflicts abandoned by farmers, the thing that led to widen gap of food security in Sudan.
\end{abstract}

Keywords: Economics of Agricultural Production, Food Security, Economic Resources, Sudan

\section{INTRODUCTION}

In the recent years, there has been an increasing development in the application of economic theory in the fields of agriculture, especially the economies of agricultural production, agricultural marketing, agricultural planning, agricultural finance and agricultural policies. The Agricultural Production Economies Branch examines all aspects of resources used and agricultural production rates that maximize the economic welfare of consumers (Naji, 2015:5).

This branch of science has become a significant one for its contribution to food security, providing raw materials for many manufacturing industries, and increasing the competitive advantage of agricultural products in the global marketplace (AMF Report, 2004: 1).

The issue of agricultural production is one of the most critical issues affecting food security in any country for the reason that it has an impact on supporting the national economy. Despite the fact that Sudan possesses substantial natural resources and geographic constituencies that qualify it to raise the rates of agricultural production, which ranges from disproportionate to the potential natural and human resources and if invested in meeting the needs of the population, it will reduce the financial obligations of the state in the balancing of food trade (Al-Buraq, 2015: 71).

Sudan is characterized by the possession of vast areas of agricultural land and water from multiple sources; the most important of which is the Nile Basin, groundwater, river flows, seasonal valleys and rains. Moreover, it is rich with natural and human resources, in addition to abundance of livestock and fisheries. All these potentials could make Sudan a pioneer country in the production of various crops, particularly the basic foods (Sorghum, Millet and wheat) which contribute to achieving the food 
security. Despite those above, the agriculture sector still encounters many problems and threat the limit the development of national economy. The main problems are the lack of funding for the development of this sector and the imposition of fees and taxes on farmers and security reasons, especially in conflict areas such as Darfur where many basic food crops are grown such Sorghum and wheat, in addition to there are causes of administrative and financial corruption, which led to the deterioration of agricultural production in general and production of food crops in particular sorghum, and millet and the reduction of their contribution to achieving food security (Khalaf, 2014:3).

\section{Research Problem:}

Sudan has an abundance of natural, water and human resources, as well as livestock, fisheries and climate diversity. Agricultural production still faces many problems and challenges, notably poor funding, lack of production inputs, scarcity of fuel, scarcity of cash and fees and taxes on farmers, fluctuation of rain, and displacement of workers due to the security conditions that force them to abandon their farms. All these factors triggered the agricultural sector to encounter obstacles in various fields, whether in the production of crops or the creation of essential foodstuffs (sorghum, millet and wheat). From the abovementioned, the problem can be stated by the following question:

Do growing essential food crops (sorghum, millet and wheat) contribute to achieving the food security in Sudan?

\section{Research Objectives:}

This research aims to identify the concept of economies of agricultural production, the objectives of economies of the agricultural output and factors of the agricultural output, as well as the concept of food security and its dimensions. It also addresses the reality of the economics of agricultural production in Sudan (the case of sorghum, millet and wheat) and the extent of their contribution to achieving food security in Sudan.

\section{Research hypotheses:}

The research assumes that inadequate funding for agricultural production, lack of inputs for production, scarcity of cash and fuel, imposition of taxes and fees on farmers, security problems in agricultural production areas, in addition to the fluctuation of rain, and lack of agricultural research in the field of agricultural production economies pertaining to basic food crops (sorghum, millet and wheat) and their role in achieving food security, and all that has negative impact on food security in Sudan. Thus make the contribution of these crops limited in achieving food security.

\section{Research Method:}

This research was based on the deductive approach in formulating the problem, hypotheses, historical and analytical approach in presenting data on the economics of agricultural production and its role in achieving food security in Sudan during the period 2015-2018, (a case study of sorghum, millet and wheat). The research also adopted the case study approach to reach accurate results that lead to recommendations and benefit the future of agricultural production in Sudan.

\section{The Concept of Economies of Agricultural Production:}

"Economies of agricultural production" is defined as an applied science in which the principles of choice are applied in the use of capital, human, land and resources management in the agricultural industry (Naji, ibid: 5). It is the application of the principles of choice to the use of capital, labor, land and management in agriculture in a way that maximizes production or reduces costs or both to achieve maximum satisfaction consumers.

\section{Objectives of Agricultural Production Economies:}

This type of science aims to explain how to reach the most efficient use of agricultural production elements (from the point of view of consumption economics), and to help farmers achieve their goals by obtaining the maximum profit possible. Thus it is concerned with the use of labor, capital, land, management and income derived from their use in order to minimize, reduce farm costs and maximize farm profitability. In general, the economics of agricultural production is concerned with all phenomena related to economic efficiency of using agricultural resources. In detail, the objectives of agricultural production economies can be redefined as follows:

1. Assessing and describing the conditions that must be met for the best use of agricultural economic resources in the production of animal and plants.

2. Determining the extent of deviation from the optimal use of agricultural economic resources compared to the optimal agricultural production processes.

3. Identifying the analytical relations of the forces that determine the production systems and the use of agricultural production elements.

4. Identifying the ways and means by which the optimal use of agricultural economic resources can be reached.

\section{Agricultural Production Factors:}

Many economists have agreed that production is viewed as creating or increasing benefits. In this area, the benefit is divided into:

Formal benefit: means a change in the shape of the material such as the conversion of elements in the soil to a crop. 
Spatial benefit: means the transfer of a crop to a place where the benefit derived from it rises. For instance, moving the wheat crop from its place of production where supply is high to consumption centres adds spatial benefit.

Then there is a time benefit arising from storing crops to a time when they are more useful.

Finally, proprietary benefit means increasing the value of a commodity when it is transferred from individuals for use to consumers who can benefit from it.

The elements of production are divided into land, labor, capital and organization, to which we may refer: (Thamer \& Samurai, without date)

\section{First: Land}

Land in its broad sense includes all-natural phenomena that deal with agricultural crops through soil. This includes the surface of the earth and its different uses, as well as the mineral content of the ground and water have beneficial effects in feeding plants, in addition to the envelopment of the earth's distinct atmosphere with varying degrees of temperature and humidity, which together lead to the comparative advantage in producing certain crops.

The land has some characteristics that distinguish from other economic resources, including:

- It is a gift of nature and it is not a human effort.

- It is sustainable, i.e. has a permanent characteristic where it can maintain its natural force.

- It is limited in quantity and stability in place, and although it is possible to increase the area of agricultural land, they constitute only a small percentage of the total agricultural area in the world.

Finally, land supply is inelastic in some cases because it is difficult to move from one place to another.

In terms of the nature of agricultural land uses, the resource mix used for crop production varies, with the wavering intensity of the use of productive elements per unit area (acre) (such as intensive agriculture) meant to increase the use of labor and capital per unit of land.

The proportion of the first component is increasing compared to the second in countries with high labor supply and where capital is scarce. This type of agriculture often predominates in such countries, while capital increases compared to work in advanced agriculture and where substitution is possible.

(Light agriculture), which is intended to decrease the proportion of the use of agricultural production components compared to the unit of land, and this type often prevails in countries characterized by an abundance of agricultural land component and low population density and thus low labor supply. Agriculture is also divided in terms of use into (specialized agriculture) and (diversified agriculture).

(Specialized agriculture) is that the farm is dominated by one type of crops in addition to extra or complementary crops, and therefore, the income of the cultivated crop constitutes a distinct proportion of farm income.

(Diversified agriculture) means the production of several crops by the farmer. therefore, the income comes from the total income of projects or the income from the crops grown by less than $50 \%$ of farm income.

\section{Second: Labor}

Labor means the effort exerted by the individual to achieve a benefit. Or it is an effort to satisfy the needs of the individual and society, and given the importance of this element in the production process. Some economists have argued that the value of the commodity is determined by the volume of work spent, while others emphasize that the value of swapping any commodity depends on the amount of work needed to produce it. The work/labor has several characteristics, including:

- The effort should be aimed at achieving benefit.

- The work is characterized by a low mobility flexibility compared to capital.

- The supply of labor tends to be independent of the demand for it. If the demand for work suddenly increases for one reason or another, the supply of labor cannot increase at the same speed and vice versa as well.

Modern agriculture requires a division of labor to achieve high productivity efficiency. In other words, farm work is divided into several operations and carried out by several individuals on large farms, because irrigation is specialized work, and marketing operations are different work requires skills other than those used in irrigation processes. While all farm operations in traditional agriculture were carried out through the individual farmer on his farm. The division of farm labor is often linked to the size and nature of the farm. The larger the farm, the more the division of labor becomes more necessary in addition to the size of the market dealing with agricultural commodities produced.

\section{Third: Capital}

Capital is a product of high relative importance in modern agriculture. It is defined as the wealth that is used to produce another wealth. It is more general and refers to the total number of machines, tools and other fixed production inputs used in agricultural production. Its importance is evident in developing countries where it is scarce compared to other factors of production. Capital formation in agriculture is a matter of progress in agricultural production and its means, and investment in this area often depends on public activity as an investment in agriculture, such as land reclamation and dam construction, has mediumterm returns. Hence, individual capital targets return in the near term and do not want this type of investment.

The size of investment is related to the size of savings and hence related to the interest rate and the marginal adequacy of the invested capital. 


\section{Fourth: Administration and Management}

Management is the decision-making by the director and the administrative process undertake five stages:

- Planning

- Organization

- Directing

- Coordination

- Control

In this regard, farm management is one of the main tools in the production process. This is because of its active role in the redistribution of agricultural economic resources, and link them in a manner that achieves optimal levels of results by placing economic resources in their efficient use.

\section{The concept of food security:}

There are many definitions of food security as a result of divergent viewpoints:

- Countries can provide the necessary food needs of the entire population in critical, emergency and exceptional cases.

- Countries can provide the most critical strategic food commodities to the population at the time of need in the quantity and prices appropriate.

- It is to provide adequate food to ensure a healthy and productive life for all citizens at all times.

Definition of the FAO World Food Summit for Food Security, which states:

Global food security is achieved when all people, at all times, have physical and economic access to adequate, safe and nutritious foods that meet their nutritional needs and suit their dietary preferences to lead an active and healthy life.

Definition of for Food Security through UN documents as follows:

"The provision of food in sufficient quantities, stable, sound, good quality and nutritious to meet the needs of all citizens and enable them to obtain it." The Arab Organization for Agricultural Development adopted this definition with the addition of food insurance from Arab sources (Adam, 2016).

The perception of the vital area in which food security must be provided has varied. While some believe that food security should be provided globally, others believe that food security should be at the regional level, i.e. the region can produce enough food for the need of its population. Some people even exaggerate the belief that food security must be at the level of each country so that its plans and programs to provide food to prevent it from affecting or control any source of food. This concept of food security does not in any way mean the ability of the state to secure all their food needs from their own resources. However, the degree of food security enjoyed by each country depends on the following conditions:

1. Producing the largest amount of food resources on the basis of comparative advantage and economic feasibility that meet the demand for food inside and outside the country.

2. The production of basic food crops in sufficient quantities according to the needs of the population for its own resources or the resources of the country or other friendly countries.

3. Providing a stockpile of sufficient basic foodstuffs for the population's requests for food for as long as possible, not less than six months.

4. Achieving the largest percentage of the general trade balance according to stable trade bases and fair competitive bases.

5. A self-negotiating force, or through membership in a regional or non-regional alliance that ensures food security and handling on fair, economically and politically appropriate terms.

The concept of food security seems to be pragmatic and unprepared as ideological concept. At the national level, the search for food security and the desire to permanently control the financing of the population do not mean dispensing with exchange or cessation of imports. However, it should be more available than external funding (Assayed, Nada 2009: 31).

In brief, under current circumstances, food means that the country produces as much food as it needs in an economically balanced manner, taking into account the comparative advantage of that country in producing the food commodities it needs. Moreover, its products be able to compete with foreign products if necessary, and have agricultural or industrial exports or both. Once exports are implemented, the country will be provided with the hard currency to import food that does not have the comparative advantage of production locally and to provide all its citizens enough food necessary for health. Also taking into account the fair distribution of food to each member of the population, especially those with limited incomes, and at the same time achieve a sufficient strategic stock of food to resort to in natural and abnormal conditions or disturbances such as political tensions and others. (www.uaeec.com/articles-1293.htm.)

\section{Dimensions of food security:}

Man has known the issue of food security as a social phenomenon since ancient times and relied on an attempt to survive by controlling its nature and cruelty and volatility. It is a complex issue characterized by complexity in the existence of several dimensions, each of which has significance, and we recall among these multiple dimensions four basic ones including the demographic dimension, economic, political and cultural.

1. Demographic dimension: The human element intervenes in three aspects. Firstly, food security for itself and its survival. Therefore, there have been many methods and methods since his social existence and developed according to the 
circumstances he is living and expected to occur. Secondly, human beings are the catalyst for producing and sustaining production, considering that these two processes are fundamental to the embodiment of self-food security in a highly efficient manner. This is evident in the staggering population growth rate experienced by the whole world, especially the Arab countries in the past years, and is one of the justifications for the food security problem in the Arab region. The size of the population has accelerated dramatically, (Belgasem, 2009:13) and the quantitative increase of the population was accompanied by a fundamental change in the distribution of the population between rural and urban areas. A qualitative increase or a quantitative increase has an unlimited effect on food security.

2. Economic dimension: It is directly related to food security, as it is embodied in the quantity and quality of agricultural production. In addition, it is necessary to share the elements of production in the production process, such as capital, labor (human resource) and land. Technical and agricultural mechanization, increased storage and marketing, and funding policies in support of food security.

3. Political dimension: The State shall be the body responsible for providing food to the society, without exception. This is through a series of resolutions that reflect their will to achieve food security, which has become the only way out of the countries in crisis, especially food shortages. The range of decisions and actions taken by States to eliminate problems that impede agricultural development or help to promote the process of agricultural development to achieve food security for all members of society falls within the political dimension. (Osman \& Bob, 2007 - 2011: 7-8).

4. Cultural dimension: It differs from the aforementioned dimensions altogether, because it does not require a political decision or order to be implemented or depends on the amount of capital invested in it, because the dimension here is very much related to the quality of the beliefs of the individual and the significance of those beliefs within the state and work, and the value of work. Hence, the cultural dimension of peoples entails the enhancement of the food security strategy adopted by the State, in which members of society should participate. However, the impact of the cultural dimension on food security is not only intended as much as it means the ability of members of society to find multiple ways and commensurate with their situation and circumstances and this falls within the framework of the right of community members to self-determination mixed with the right to food (Mohamed, 2006: 17). Many countries, including Sudan, urge that the value of labor, such as communal work (Al-Nufir) and other collective and solidarity actions in the field of food security, be raised, and that land is a great heritage that must be preserved (Osman \& Bob, ibid:8).

Agricultural production in Sudan during the period 2015/2016 - 2017/2018 (a case study of sorghum, millet and wheat) and its role in achieving food security:

Agricultural production economies are one of the most important fields of employment and sources of income for a large segment of the population in many countries, including Sudan. In addition, agricultural production contributes to achieving food security and providing raw materials for many manufacturing industries. Many Arab countries have focused on agricultural production to acquire a decent position in world markets to maximize economic benefits and increase the competitive advantage of Arab agricultural products in world markets. Sudan, like other Arab countries, has been interested in agricultural production. Agriculture is one of the most important sources of livelihood for the population. Working in this sector together with the livestock sector, more than $65 \%$ of the total population is assisted by the large area of this country. Despite the availability of water, Sudan suffers from many obstacles that hinder the development of agricultural production, especially the lack of adequate funding, especially before the start of the agricultural season, and the fluctuation of rain that leads to fluctuation of agricultural production from year to year, and the lack of mechanisms Agricultural Production the lack of effort exerted by the state in the rehabilitation of road networks for agricultural projects.

In Sudan, there are four main types of agriculture, and these vary according to the method of production associated with them, and the type of irrigation followed, and these types are: (https://mawdoo3.com).

*Agriculture by Irrigation: It depends on industrial irrigation, covering $25 \%$ of the cultivated area, which in turn is divided into the following:

- Flow Irrigation, which draws water from reservoirs and dams, such as Roseres Dam, and Khashm Al Gaerbah.

- Irrigation by pumps, which are pumps gets water from the river.

- Flood irrigation, which depends on periodic floods, such as that occurs in the Delta of Gash River.

*Rainfed Agriculture: Depends on rainfall, occupies about 25\%. Also of the total agricultural area in the country.

* Mechanized Agriculture: used machines in their production processes.

* Traditional agriculture: It is followed in the countryside and the outskirts of villages.

\section{MATERIAL AND METHODS}

Sudan is growing many food crops, the most important of which are sorghum, wheat and millet. It also produces many oilseeds, the most important of which are peanuts, sesame and sunflower. This research will focus on the most important food crops (sorghum, millet and wheat).

Table (1) shows the production of the most important food crops of sorghum, millet and wheat during the period (2015/2016 2017/2018).

Table 1: Production of the most important food crops (2015 / 2016-2017 / 2018). (Central Bank of Sudan reports, 2017, 2018). 
Citation: Elfatih Mohamed Osman Mukhtar. 2019., The Role of Agricultural Production Economies in Achieving Food Security in Sudan during the Period (2015-2018). (A Case study of Sorghum, Millet and Wheat). Australian Journal of Basic and Applied Sciences, 13(11): 19-27. DOI: 10.22587/ajbas.2019.13.11.3

(Area: thousands of acres), (Production: thousands of metric tons), (Productivity: kg/acre)

\begin{tabular}{|c|c|c|c|c|c|c|c|c|c|}
\hline \multirow{2}{*}{ Season } & \multicolumn{3}{|c|}{ Sorghum } & \multicolumn{3}{|c|}{ Millet } & \multicolumn{3}{|c|}{ Wheat } \\
\hline & $\begin{array}{c}\text { Cultivated } \\
\text { Area }\end{array}$ & Production & *Productivity & $\begin{array}{c}\text { Cultivated } \\
\text { Area }\end{array}$ & Production & *Productivity & $\begin{array}{c}\text { Cultivated } \\
\text { Area }\end{array}$ & Production & *Productivity \\
\hline $2015 / 2016$ & 19.832 & 2.744 & 222 & 7.120 & 486 & 120 & 548 & 779 & 1.400 \\
\hline $2016 / 2017$ & 27.212 & 6.441 & 287 & 9.813 & 1.457 & 202 & 636 & 563 & 923 \\
\hline $2017 / 2018$ & 21.060 & 3.904 & 251 & 8.300 & 878 & 147 & 419 & 463 & 1.129 \\
\hline
\end{tabular}

Source: Ministry of Agriculture and Forestry, General Directorate of Agricultural Planning and Economy.

* Productivity represents the product divided by the harvested area.

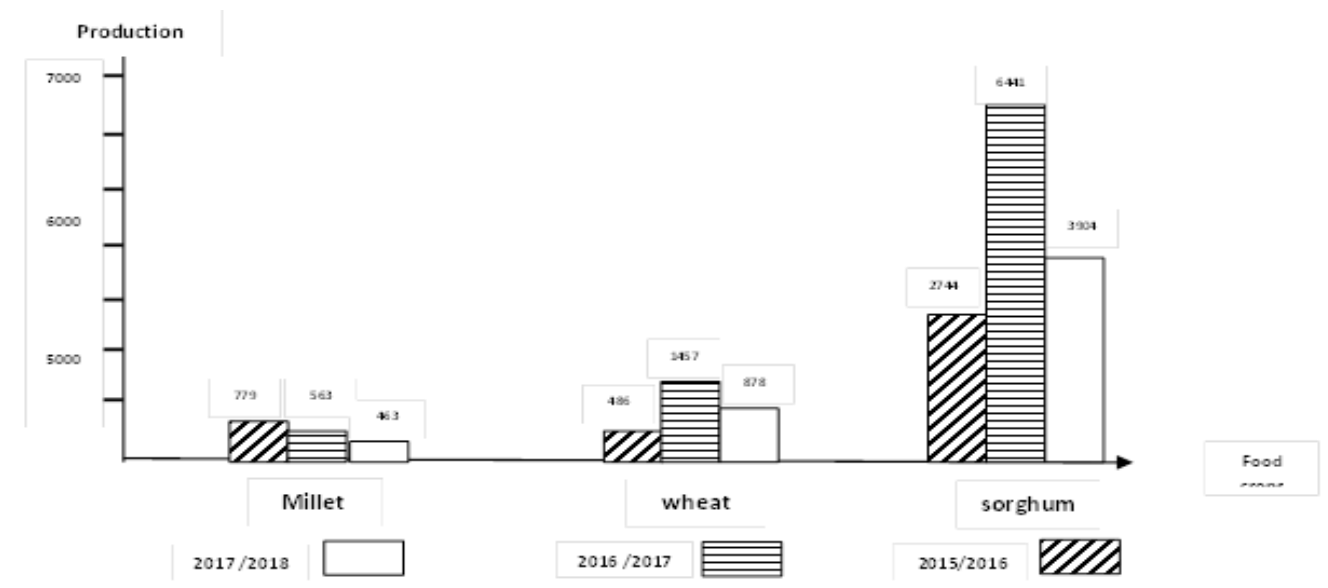

Figure 1: Shows the most important food crops during the period of the study.

Figure 1: The Production of the most important food crops for the seasons 2015/2016 - 2017/2018

Sudan is considered one of the largest Arab and African countries, and the arable area is estimated at 200 million acres or one-third of the area of Sudan, but only a small part of it is currently invested, (www.sudapedia.sd/ar/content/17) With the arable space and enormous potential that this country possesses of natural and human resources. It is clear that the cultivated area is modest compared to the arable area and does not exceed $11 \%$ on average during the study period for the sorghum crop. In 2017/2018, sorghum production dropped significantly to 3,904 from 6,441 in 2016/17, as shown in Table (1) and Figure (1). The modest cultivated areas and the modest production of the sorghum crop during the study period were due to poor funding, tight liquidity and fuel, and imposing taxes and fees on farmers. In addition to the instability of security in some areas where this crop is grown, especially Darfur, where the cultivation of sorghum in Sudan in the following areas:

- Traditional rainfalls in Kordofan, Darfur, Batana, Blue Nile and Sennar.

- Automatic rainfalls in Gedaref, Nuba Mountains, Blue Nile and Sennar.

- $\quad$ Irrigated agriculture areas in Gezira, Rahad, Suki, New Halfa, Tokar Delta and Gash Delta.

- Catering projects in the state of the White Nile (Ministry of Agriculture, 2015).

As for millet, it is the food for most of the population of western Sudan (Kordofan and Darfur states), the second most important crop after sorghum, and its cultivation extends mainly in the sandy lands (Gizan) that occupy the northern parts of Kordofan and Darfur, which are marginal areas of low rainfall rates are mostly over $400 \mathrm{~mm}$ per year, making millet the main food crop that other grain crops such as sorghum cannot compete in this dry environment. Millet cultivation relies on rain with limited area under irrigation in Tokar. By referring to Table (1), it is clear that the cultivated areas of millet are very modest during the study period compared to the arable areas in Sudan, and compared to the cultivated areas of the sorghum crop, and the fluctuation in the cultivated areas shows the fluctuation of rain. Millet production, despite its rise in 2016/17 to 1,457 compared to $2015 / 16$ (486), has decreased in $2017 / 18$ to (878) by $39.7 \%$ due to decrease in cultivated area and decrease in productivity by $15.4 \%$ and $27.2 \%$. The decrease in millet was due to several obstacles, including:

- $\quad$ Lack and fluctuation of rain.

- An infestation of pests and diseases.

- Security instability.

- Farms do not follow modern scientific methods such as the use of pesticides and fertilizers because of poor agricultural financing with the high cost of production.

As for the wheat crop, it is one of the most important and oldest types of food grains, the most valuable and the most widespread, and is grown in northern Sudan (the state of the River Nile and northern) since ancient times, and in recent decades, Sudan's consumption of wheat has increased from less than one hundred thousand tons per year to the gap between consumption and production is covered by importation from abroad, which has placed a heavy burden on Sudan's foreign exchange resources and has sometimes become a political pressure factor. Currently, wheat is grown in Sudan in winter, depending on the irrigated system in the following areas: 
- Northern State - Nile River State - White Nile State - Irrigated Projects in Gezira, Rahad and New Halfa (Ibrahim 2010). By referring to Table (1), it is clear that wheat production decreased from 779 thousand metric tons in 2015/16 season to 536 thousand metric tons in 2016/17 season, and wheat productivity continued to decline from 536 thousand metric tons in $2016 / 17$ season to 463 thousand metric tons in $2017 / 2018$ at a rate of $17.8 \%$ due to the shrinking of the cultivated areas by $34.1 \%$, despite the increase in productivity by $21.5 \%$. The fluctuation of cultivated areas, production and productivity of the wheat crop is due to the lack of timely funding for the farmer, the imposition of taxes and fees on farmers, and the failure to provide different inputs to the farms in a timely manner.

It is clear from the previous presentation of the most critical food crops during the study period that the cultivated areas and production were not at the level desired by the population of Sudan, which exceeds 40 million people. This is confirmed by the 2018 UN report, which showed that there has been a sharp increase in the prices of basic foodstuffs in Sudan, which has negatively affected food security. Based on household survey and price monitoring data, it is believed that the majority of the population is unable to afford the local food basket. The United Nations report indicated that the average price of sorghum at the level of the states of Sudan in the period 2015-2018 increased by 96 to 236\%, (UN report, 2018). This drastic rise in prices is due to weak government spending (finance) for the agricultural sector, especially basic food crops, and the focus on giving the highest priority to spending on the defense and security sector at the expense of vital sectors such as the agricultural sector, which provides the living requirements of the vast majority of the population. The heavy government taxes and fees imposed on this sector have caused many farmers to be reluctant to work, which has negatively impacted production and high prices, which were a direct cause in 2018 for widespread protests across Sudan. The sharp rise in the prices of consumer goods, as well as the lifting of subsidies on wheat, which doubled the amount of bread. The neglect of the sector has caused the country's foreign exchange earnings to decline, the value of the Sudanese pound and the lack of imported strategic goods, including fuel, forcing citizens to wait long hours, some overnight, in several kilometres of gas stations across Sudan's urban areas. This severe shortage occurred in the preparation period for the critical agricultural season, which threatened the risk of endangering internal food production and agricultural exports for 2018 .

Measures taken by the government to control the amount of money circulating in the economy by directing banks to limit withdrawals and restricting clients' access to their balances have also led to a decline in food crop production in 2018, as shown in Table (1) for crops (sorghum, millet and wheat). As a result of these measures, the banking system has lost the confidence of citizens and the interaction between individuals and banks has become extremely complex, resulting in a liquidity crisis that peaked by August 2018 when people were unable to withdraw their salaries from banks.

All this has significantly affected the production of the main food crops, and led to the rise in prices, inflation rates jumped from $33.1 \%$ in October 2017 to $52.4 \%$ in January 2018 and even rose again from $63.86 \%$ at the end of June 2018 to $63.94 \%$ by the end of July 2018. According to these rates, implied annual inflation has jumped to 137\%, making Sudan the third largest globally after Venezuela and Iran (Steve Hanke: https://twitter.com/stevehanke/status/1021977795-5854200835 ).

Figure 2 shows the inflation rate from December 2015 to July 2018 (CBS report, 2018)

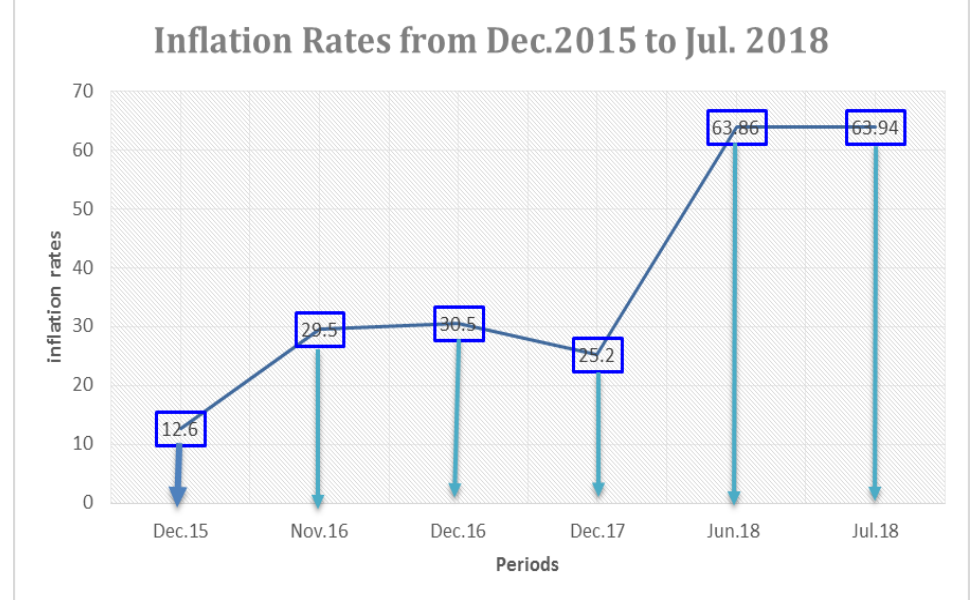

Figure (2) inflation rates from December 2015 - July 2018

The 2018 UN report showed that the humanitarian situation in Sudan has become more complex, as the increase in food prices has made millions of people unable to afford the basic food basket. In addition, the recent fuel shortage has affected the delivery of humanitarian assistance to the most vulnerable communities. The 2018 UN-coordinated Humanitarian Response Plan for Sudan has launched an appeal for US \$ 1.4 billion, and donors have provided about US \$ 232 million this year, most of it directed towards food aid (UN report, 2018). Achieving food security in Sudan during the study period was limited and led to the emergence and aggravation of the food deficit problem despite the enormous resources

\section{RESULTS AND DISCUSSION}

Results and recommendations:

First: Results 
1- The study showed that Sudan is a rich country with many natural resources represented in fertile arable agricultural lands estimated at 200 million acres, different water sources and climate diversity, arable lands and the enormous potential of natural and human resources.

2- The instability of the cultivated areas for all food crops (sorghum, millet and wheat) during the study period. For instance, The sorghum cultivated area decreased from 27,212 thousand acres in 2016/2017 to 21,060 thousand acres in 2017/2018, and sorghum production for the same period decreased from 6,441 thousand metric tons to 3,904 thousand metric tons. Millet cultivated areas decreased from 9,813 thousand acres in 2016/17 to 8,300 thousand acres in 2017/2018, and millet production for the same period decreased from 1,457 thousand metric tons to 878 thousand metric tons. Also, the cultivated areas of wheat crop decreased from 636 thousand acres in 2016/2017 to 419 thousand acres in 2017/2018. Wheat production declined for the same period from 536,000 metric tons to 463,000 metric tons. The main common denominator for the decline in cultivated areas and the volume of production of all these food crops, which constitute the staple food of the population, was the lack of funding and the lack of timely production of various inputs for farmers, causing high prices of these staple foods, and its negative impact on food security.

3- The study showed that the productivity of basic food crops (millet, sorghum and wheat) is very low and worrying, especially in the last year of the study period, especially wheat crop, whose productivity decreased from 563 thousand metric tons in 2016/2017 to 463 thousand metric tons in 2017. This means that the contribution of these food crops to the food security of the population exceeding 40 million is substandard and below the level of ambition.

4- One of the main reasons that led to the modest cultivated areas and the low volume of production of the basic food crops of the population (sorghum, millet and wheat) is the imposition of taxes and heavy fees on farmers, which led to their reluctance to work and caused high prices, in addition to the lack of fuel and lack of liquidity and lack of fluctuation and rain.

5- Security instability has led to reduced productivity of sorghum and millet crops, which are concentrated in Darfur, Blue Nile State, Kordofan and the Nuba Mountains.

6- The productivity of staple food crops (sorghum, millet and wheat) did not cover domestic demand, causing the prices of these crops to rise dramatically, and confirming our findings, the 2018 UN report showed that there was a sharp increase in the prices of staple foods in Sudan that affected The majority of the population is believed to be unable to afford the local food basket, with inflation in July 2018 at almost $64 \%$.

7- The focus on giving high priority to government spending to the defense and security sectors and a clear bias against the agricultural sector, which provides the livelihood requirements of the vast majority of the population, contributed to the decline in the contribution of the agricultural sector to food security and its contribution to GDP and significantly reduced the country's revenues from cash Foreign currency and the devaluation of the Sudanese pound.

\section{Second: Recommendations}

1. Great attention to the agricultural sector, in general, is highly recommended with more focus in the first phase on supporting basic food crops (sorghum, millet and wheat), and raise their share of public investments to reach self-sufficiency and then move to the export phase.

2. Terminating negative policies that threaten the production of basic food crops (sorghum, millet and wheat), such as imposing heavy taxes and fees on farmers that lead to their reluctance to work and high prices.

3. Achieving peace and security stability in areas where basic food crops are grown such as Darfur, Blue Nile State and Kordofan so that farmers can settle in their farms and devote themselves to their work and contribute to food security.

4. To stop concentrating government expenditure on certain sectors and to achieve a balance in government spending between different sectors and to focus on the agricultural sector, especially the basic food crops that are directly related to the lives of citizens such as sorghum, millet and wheat.

5. Encouraging the private sector to invest in agricultural and food fields, especially basic food crops such as sorghum, millet and wheat, and enacting appropriate laws that help attract local and foreign investors to invest in this field to increase the supply of basic food products, stabilize prices and reduce inflation. The high of $63.94 \%$ in July 2018.

6. Conducting more agricultural research in the field of agricultural production economics to use modern practical methods in production to develop this vital sector which helps in achieving sustainable development.

\section{CONCLUSION}

This research dealt with the role of economies of agricultural production in achieving food security in Sudan during the period 2015 - 2018 (a case study of sorghum, millet and wheat). The research explained the concept of economies of agricultural production and its objectives, and factors of agricultural production, as well as the concept of food security and its dimensions, and then addressed the analysis of agricultural production in Sudan during the period 2015/2016 - $2017 / 2018$ (case study of sorghum, millet and wheat) and its role in achieving food security.

The research shows that Sudan has enormous natural and human resources, with an estimated arable area of 200 million acres, but despite this potential, the exploitation remains very limited and did not exceed 27.212 thousand acres during the study period due to poor government funding for this vital sector. Many of the negative practices towards the agricultural sector and farmers, which forced them to refrain from work, and the production of basic food crops (sorghum, millet and wheat) did not live up to the hopes and aspirations of the Sudanese people, but did not cover internal demand, and this caused the rise in prices of these food crops. This has had a negative impact on food security so that the majority of the population is unable to afford the local food basket. 


\section{REFERENCES}

Adam, Al-Hadi, Food Security of Wheat Commodity in Sudan (2001-2014), Journal of Economic Sciences, Sudan University of Science and Technology, Vol. 17, No. 1, 2016.

Al-Buraq, Abbad, The Elements of Agricultural Production in the Tihama Plain and its Role in the National Economy of the Republic of Yemen, Al-Nasser Magazine, Faculty of Arts, Zammar University, Volume 1, Issue 6, July - December 2015, p. 71.

Arab Monetary Fund, Consolidated Arab Economic Report, 2004, p. 1.

Assayed, Nada (2009), Food Security in Sudan: A Standard Model for Wheat and Sorghum Commodity, Unpublished PhD Thesis, Sudan University of Science and Technology, p. 31.

Belgasem, Solatania (2009), Illustrative treatment of the concept of food security and its dimensions, Journal of the Faculty of Arts and Humanities, No. 5, Algeria, p. 13.Central Bank of Sudan reports, 2017, 2018.

https://mawdoo3.com

https://twitter.com/stevehanke/status/1021977795-5854200835.

Ibrahim, Muzammil (2010), Climate Impact on Wheat and Fruit Production in the Northern State, Unpublished Master Thesis, University of Khartoum, Sudan.

Khalaf, Bassem, the importance of agricultural investment in achieving food security in Iraq, Journal of the Baghdad College of Economic Sciences, College of Management and Economics, the number of the fifth scientific conference, University of Baghdad, 2014, p. 3, (disposition).

Ministry of Agriculture, Department of Agricultural Statistics, 2015.

Mohamed, Mohamed El-Fateh (2006), Features and Strategies of Food Security in Sudan, An Analytical Study at the National Level 1990-2003, Unpublished Ph.D. Thesis, Al-Neelain University, Sudan, p. 17.

Naji, M. Ibrahim (2015), Economies of Agricultural and Industrial Production, 1st Floor, Amjad Publishing and Distribution House, Amman, p. 5.

Naji, Mohammed Ibrahim, ibid p. 5.

Osman, Kamal, Bob, Essam, Analysis of Food Security Policies in Sudan: 2007-2011, Al-Neelain University, Khartoum, pp. 7-8, (Adapted).

Osman, Kamal, Bob, Issam, previous source, p. 8.

Report of the Central Bank of Sudan 7/2018.

Thamer, Hassan, and Samurai, Faculty of Agriculture, University of Tikrit, Iraq, nd.

United Nations report, World Food Program, 2018.

United Nations report, World Food Program, 2018.

www.sudapedia.sd/ar/content/17 .

www.uaeec.com/articles-1293.htm. 